\title{
Rapid Photonic Processing of High-Electron-Mobility PbS Colloidal Quantum Dot Transistors
}

\author{
Mohamad I. Nugraha,* Emre Yarali, Yuliar Firdaus, Yuanbao Lin, Abdulrahman El-Labban, \\ Murali Gedda, Elefterios Lidorikis, Emre Yengel, Hendrik Faber, and Thomas D. Anthopoulos*
}

Cite This: https://dx.doi.org/10.1021/acsami.0c06306

Read Online

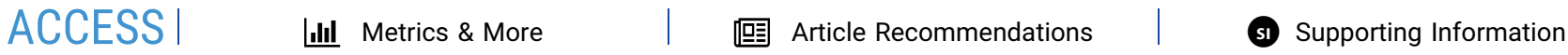

ABSTRACT: Recent advances in solution-processable semiconducting colloidal quantum dots (CQDs) have enabled their use in a range of (opto)electronic devices. In most of these studies, device fabrication relied almost exclusively on thermal annealing to remove organic residues and enhance inter-CQD electronic coupling. Despite its widespread use, however, thermal annealing is a lengthy process, while its effectiveness to eliminate organic residues remains limited. Here, we exploit the use of xenon flash lamp sintering to post-treat solution-deposited layers of lead sulfide ( $\mathrm{PbS}$ ) CQDs and their application in n-channel thin-film transistors (TFTs). The process is simple, fast, and highly scalable and allows for efficient removal of organic residues while preserving both quantum confinement and high channel current modulation. Bottom-gate, topcontact $\mathrm{PbS}$ CQD TFTs incorporating $\mathrm{SiO}_{2}$ as the gate dielectric exhibit a maximum electron mobility of $0.2 \mathrm{~cm}^{2} \mathrm{~V}^{-1} \mathrm{~s}^{-1}$, a value higher than that of control transistors $\left(\approx 10^{-2} \mathrm{~cm}^{2} \mathrm{~V}^{-1} \mathrm{~s}^{-1}\right)$ processed via thermal annealing for $30 \mathrm{~min}$ at $120{ }^{\circ} \mathrm{C}$. Replacing $\mathrm{SiO}_{2}$ with a polymeric dielectric improves the transistor's channel interface, leading to a significant increase in electron mobility to $3.7 \mathrm{~cm}^{2} \mathrm{~V}^{-1} \mathrm{~s}^{-1}$. The present work highlights the potential of flash lamp annealing as a promising method for the rapid manufacture of $\mathrm{PbS} \mathrm{CQD}$-based (opto)electronic devices and circuits.

KEYWORDS: colloidal quantum dots, thin-film transistors, flash lamp annealing, solution-processed semiconductors, large-area electronics

\section{INTRODUCTION}

Semiconducting colloidal quantum dots (CQDs) offer numerous advantages as bottom-up engineered building blocks for a diverse range of optoelectronic applications that include thin-film transistors (TFTs), ${ }^{1-4}$ light-emitting devices, ${ }^{5-9}$ photovoltaics, ${ }^{10-13}$ and thermoelectrics, ${ }^{14-16}$ to name a few. Their solution processability enables facile device fabrication that is compatible with a variety of scalable and cost-effective manufacturing techniques, making CQDs a promising family of electronic materials for use in large-area electronics. ${ }^{17-20}$ Fabrication of CQD devices, particularly TFTs, has so far relied on conventional thermal annealing. ${ }^{21-23}$ Despite its widespread use, thermal annealing is far from optimal as it is unable to remove entirely the insulating organic residues (ligands, solvent molecules, etc.) trapped in the layer following deposition, which often adversely affects charge transport. ${ }^{24-26}$ Annealing at higher temperatures $\left(>140{ }^{\circ} \mathrm{C}\right)$ can help to alleviate the issue of organic residues but often at the expense of quantum confinement (due to aggregation of CQDs) and transistor performance. ${ }^{27-29}$ Besides, high-temperature annealing of CQD layers limits the compatibility of the technology with inexpensive and temperature-sensitive substrate materials (e.g., polymers), thus further restricting the potential economic benefits associated with large-area manufacturing.

In CQD solids, charge carrier transport is mainly influenced by the chemistry of capping ligands employed. ${ }^{30}$ Of particular interests are halide salts, such as methylammonium iodide
(MAI), which have been used extensively to replace bulky oleic acid (OA) ligands and enhance charge carrier transport in the CQD layer. ${ }^{30}$ The atomic size of iodides provides an excellent surface passivation for CQDs, leading to $\mathrm{n}$-channel transistors $^{26,30}$ and efficient solar cells. ${ }^{25}$ Unfortunately, in the case of TFTs, the use of iodide ligands has so far yielded devices with relatively low charge carrier mobility $\left(\sim 10^{-2} \mathrm{~cm}^{2} \mathrm{~V}^{-1} \mathrm{~s}^{-1}\right)$, a result attributed to the presence of insulating organic ligands in the channel layer following ligand exchange. ${ }^{26,31}$ Longer thermal annealing at higher temperatures can remove the organic residues but results in other unwanted effects such as fusion of CQDs. ${ }^{26}$ Because of these challenges, the development of facile post-processing steps that can remove organic residues while preserving the low-dimensional nature of the quantum dots is timely.

Here, we report on ultrafast processing of lead sulfide (PbS) CQD films using flash lamp annealing (FLA). The latter resembles laser annealing, but it is easier to upscale, it is rapid, and has been used successfully for the development of various TFTs and integrated circuits. ${ }^{32-39}$ Although the process relies

Received: April 6, 2020

Accepted: June 22, 2020

Published: June 22, 2020 

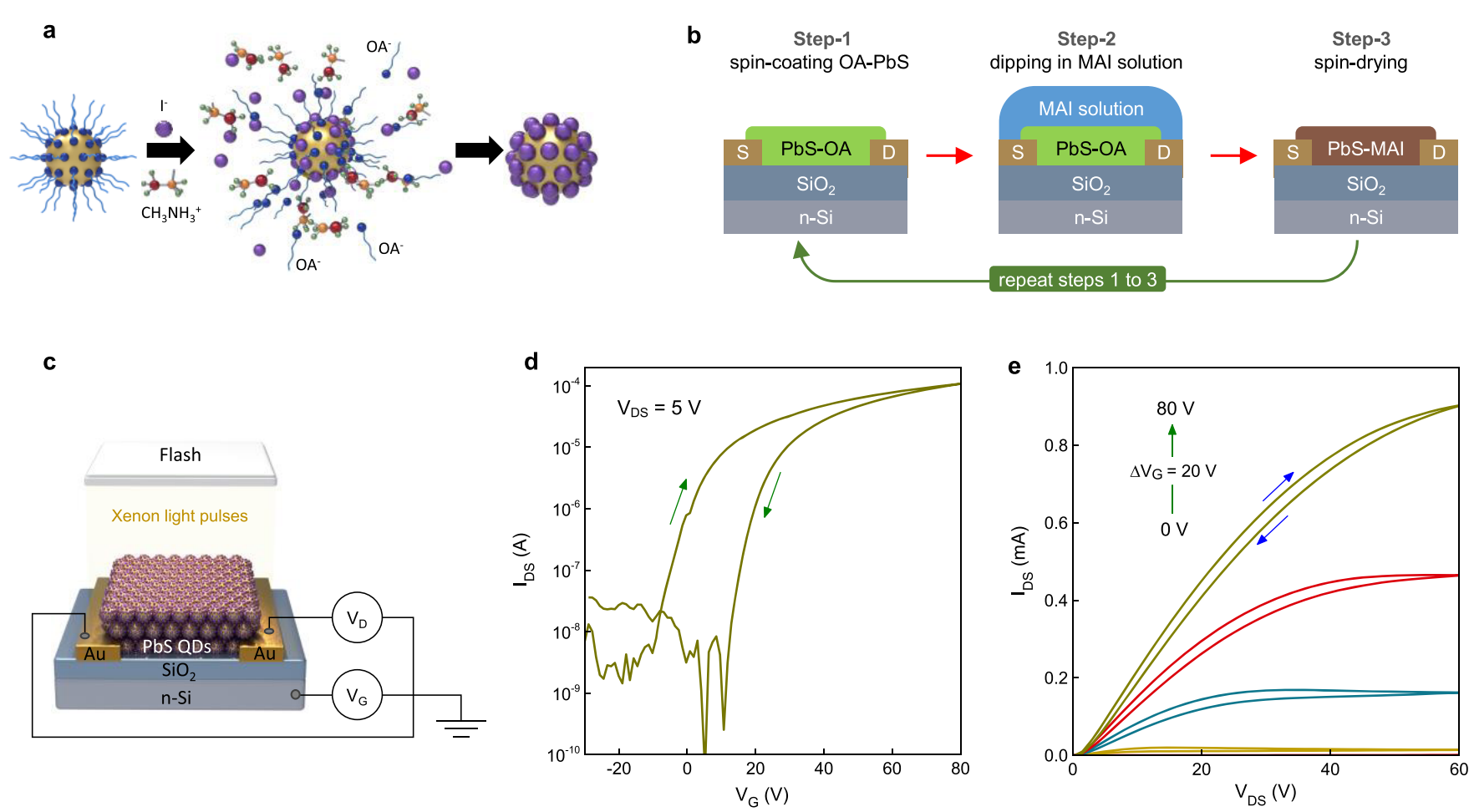

Figure 1. (a) Schematic depicting the ligand exchange in PbS CQDs used in this work. (b) Schematic depiction of the layer-by-layer film deposition process employed for the fabrication of PbS CQD TFTs. (c) Schematic of the flash lamp annealing (FLA) step of PbS CQD layers. (d) Transfer and (e) output characteristics of PbS CQD TFTs prepared via FLA using the pulse length of $300 \mu \mathrm{s}$ with the optical energy density of 2.2 $\mathrm{J} \mathrm{cm}^{-2}$ each.

on microsecond- to-millisecond-long optical pulses, we find that it can suppress the concentration of organic residues while maintaining quantum confinement in the $\mathrm{PbS} C \mathrm{CQD}$ layer. Fine-tuning the energy density of the optical pulse results in bottom-gate, top-contact (BG-TC) transistors with an electron mobility of $0.2 \mathrm{~cm}^{2} \mathrm{~V}^{-1} \mathrm{~s}^{-1}$, a significantly higher value than that obtained for control PbS CQD TFTs $\left(\approx 10^{-2} \mathrm{~cm}^{2} \mathrm{~V}^{-1}\right.$ $\mathrm{s}^{-1}$ ) processed via thermal annealing. Analyses of the chemical and optical properties of FLA-treated $\mathrm{PbS} C \mathrm{CQD}$ layers reveal the presence of a reduced concentration of organic residues and undercharged lead $(\mathrm{Pb})$ atoms. By switching to a top-gate, bottom-contact (TG-BC) transistor architecture and using poly(methyl methacrylate) (PMMA) and ion gel as the gate dielectrics, we are able to obtain PbS CQD-based TFTs with maximum electron mobility values of 0.48 and $3.74 \mathrm{~cm}^{2} \mathrm{~V}^{-1}$ $\mathrm{s}^{-1}$, respectively.

\section{RESULTS AND DISCUSSION}

PbS CQDs were first functionalized with long-alkyl-chain oleic acid (OA) ligands as they are known to enhance the solubility and stability of the resulting solutions in a broad range of organic solvents. Once assembled onto solid films, OA ligands are replaced with shorter ones bringing CQDs closer to each other, thus enhancing the electrical conductivity of the film. Here, we used methylammonium iodide (MAI) as the short ligands composed of methylammonium and iodide as cation and anion, respectively. Due to the $\mathrm{Pb}$-rich characteristics of the $\mathrm{PbS} \mathrm{CQD}$ surface, the iodide anion attaches to the CQD surface, as illustrated in Figure 1a. Deprotonated OA and methylammonium (MA) cations are expected to be removed during film deposition and post-processing steps. The deposition of the $\mathrm{PbS} \mathrm{CQD}$ films was performed via the layer-by-layer $(\mathrm{LbL})$ method, as illustrated in Figure $1 \mathrm{~b}$.
It has been previously shown that the removal of the organic residues leads to the transition from thermally activated behavior to bandlike transport in CQD films. ${ }^{16,40}$ Ellipsometry measurements suggest that thermal annealing is indeed effective in removing the organic residues and trapped solvent (Figure S1 in the Supporting Information). The PbS CQD films with OA ligands exhibit a low refractive index, which is an inherent optical property of organic molecules (OA ligands). Following MAI ligand exchange, the refractive index of the films increases significantly, indicating the successful removal of OA ligands and densification of the $\mathrm{PbS} C \mathrm{CQD}$ layer. The refractive index of the latter increases further upon annealing at $200{ }^{\circ} \mathrm{C}$ due to further decomposition and shrinkage of the organic residues. However, thermal annealing at this temperature induces aggregation of the $\mathrm{PbS} C \mathrm{CQDs}$ and suppression of the characteristic quantum confinement. As shown in Figure S2 (Supporting Information), this effect leads to a notable increase in the channel off-current with a detrimental effect on transistor's performance, hence making the layers unsuitable for TFT applications.

In our effort to decouple the need for high-temperature annealing and the loss of channel current modulation, we employed FLA as a post-deposition processing step to realize $\mathrm{PbS}$ CQD TFTs (Figure 1c). Exposing the PbS CQD layer to a short $(<1 \mathrm{~ms})$ but a high-energy pulse of xenon light leads to rapid heating of the CQD layer, leading to the evolution of high-temperature profiles across it for a very short time scale, while maintaining the substrate close to room temperature. To test the applicability of the FLA as a post-deposition step, we first applied FLA on PbS CQD TFTs by subjecting the devices to 60 consecutive pulses with a relatively low optical energy density $\left(2.2 \mathrm{~J} \mathrm{~cm}^{-2}\right.$ per pulse) and a pulse duration of $300 \mu \mathrm{s}$. The transfer characteristics of the resulting PbS CQD TFTs 

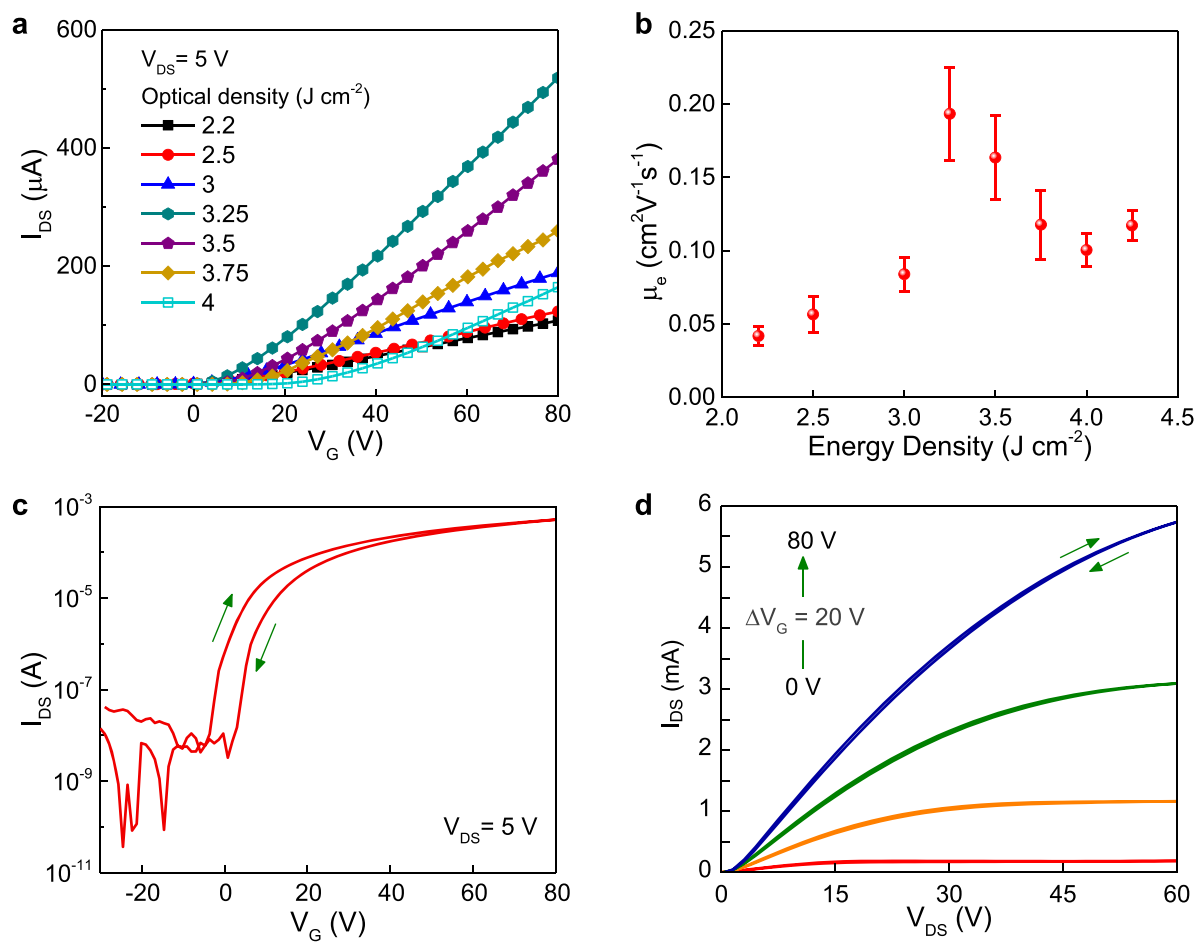

Figure 2. (a) Transfer characteristics in PbS CQD TFTs with different optical energy densities (shown in the legend), (b) electron mobility in PbS CQD TFTs as a function of optical energy density. Representative transfer $(c)$ and output $(d)$ characteristics for PbS CQD TFTs processed using an optical energy density of $3.25 \mathrm{~J} \mathrm{~cm}^{-2}$. In comparison to the devices treated with a lower flashing energy in Figure $1 \mathrm{~d}, \mathrm{e}, \mathrm{FLA}$ at $3.25 \mathrm{~J} \mathrm{~cm}^{-2}$ significantly suppresses the operating hysteresis of the devices.

are shown in Figure 1d. The devices exhibit clear n-channel behavior and excellent current modulation but with notable hysteresis between forward and reverse gate voltage $\left(V_{\mathrm{G}}\right)$ sweeps. The clockwise direction of the hysteresis indicates electron trapping of injected electrons by trap states that are still present in the channel, and will be discussed later. To estimate the electron mobility $(\mu)$ in the transistors, we used the gradual channel approximation model in the linear regime given as

$$
\mu=\frac{L}{W C_{i} V_{\mathrm{ds}}} \frac{\partial I_{\mathrm{ds}}}{\partial V_{\mathrm{g}}}
$$

where $W$ and $L$ are the channel width and length, respectively, $C_{i}$ is the capacitance per unit area (which is measured independently for each gate dielectric material used), $V_{\mathrm{DS}}$ is the source-drain voltage, $I_{\mathrm{DS}}$ is the source-drain current, and $V_{\mathrm{G}}$ is the gate voltage. Fitting eq 1 to the linear transfer curve yielded an electron mobility value of $0.05 \mathrm{~cm}^{2} \mathrm{~V}^{-1} \mathrm{~s}^{-1}$. This value is comparable to that of CQD TFTs prepared via thermal annealing at $120{ }^{\circ} \mathrm{C}$ for $30 \mathrm{~min}$ (Figure S3). Importantly, TFTs processed via rapid FLA exhibit higher channel current and significantly smaller hysteresis than the devices prepared via thermal annealing at $120{ }^{\circ} \mathrm{C}$ (Figures le and S3).

To obtain optimal device performance, we varied the energy density of each optical pulse from 2.2 to $4 \mathrm{~J} \mathrm{~cm}^{-2}$, as it was found to be the parameter with the greatest influence. As shown in the transfer characteristics of Figure 2a, the channel current gradually increases with increasing the optical energy density up to $3.25 \mathrm{~J} \mathrm{~cm}^{-2}$, followed by a monotonic decrease for $>3.25 \mathrm{~J} \mathrm{~cm}^{-2}$. The evolution of electron mobility as a function of optical energy density is shown in Figure $2 \mathrm{~b}$. A maximum electron mobility value of $0.2 \mathrm{~cm}^{2} \mathrm{~V}^{-1} \mathrm{~s}^{-1}$ is achieved in PbS CQD TFTs subjected to $3.25 \mathrm{~J} \mathrm{~cm}^{-2}$. This mobility is approximately a factor of 4 higher than that obtained for thermally annealed transistors (30 min annealing duration at $120{ }^{\circ} \mathrm{C}$ ). Figure $2 \mathrm{c}$ displays the representative transfer characteristics of optimized devices processed with an optical energy density of $3.25 \mathrm{~J} \mathrm{~cm}^{-2}$. It can be seen in Figure $2 \mathrm{~d}$ that the resulting $\mathrm{PbS} \mathrm{CQD}$ TFTs exhibit reduced operating hysteresis and low off-current (see Figure S4 in the Supporting Information for the hysteresis of the devices treated with different optical energy densities). These results highlight the potential of FLA as an alternative to the conventional thermal annealing technique for the rapid manufacturing of $\mathrm{PbS}$ CQD TFTs and other potential devices such as photovoltaics, photodetectors, and thermoelectrics.

Further insight into the optothermal dynamics across the TFT structure during FLA was obtained using coupled optical and thermal simulations (Figure S5a-c). Further details on the methodology employed are provided in the Methods and Supporting Information sections. We find that under a maximum fluence of $4 \mathrm{~J} \mathrm{~cm}^{-2}$, each successive $0.3 \mathrm{~ms}$ pulse causes an instantaneous temperature increase $(\Delta T)$ in the $\mathrm{PbS}$ CQD film of about $80 \mathrm{~K}$ above the average device temperature (Figure S5d,e). The device temperature, on the other hand, is determined by the heat conduction between the back-side of the device and the holder. If we assume a back-side convection flux $j=h \Delta T$, with $h=100 \mathrm{~W} \mathrm{~m}^{-2} \mathrm{~K}^{-1}$ (an approximate value for forced air cooling), then the device's long-time average saturation temperature is $230 \mathrm{~K}$ (established after 30 consecutive pulses at $1 \mathrm{~Hz}$ ) (Figure S5f). Under these conditions, the $\mathrm{PbS} \mathrm{CQD}$ layer is expected to experience a maximum $\Delta T$ of approximately $310 \mathrm{~K}$. In reality, however, our sample rests on a metallic holder, and a higher convection flux should exist. If we assume an upper limit for $h=1000 \mathrm{~W} \mathrm{~m}^{-2}$ 

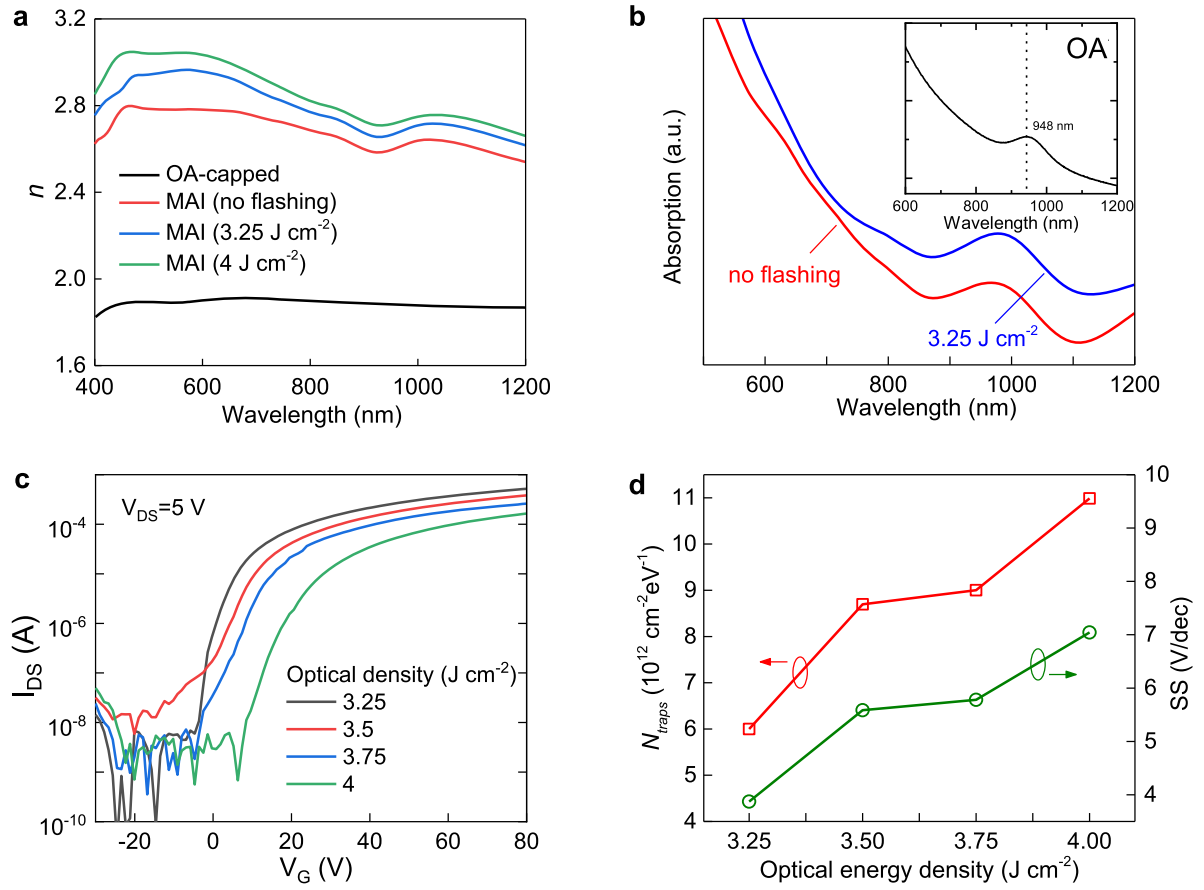

Figure 3. (a) Refractive index (n) in PbS CQD films after flashing at different optical energy densities. (b) Absorption spectra of PbS CQD films before and after flashing with $3.25 \mathrm{~J} \mathrm{~cm}^{-2}$. The inset shows the absorption of $\mathrm{PbS}$ CQD films with OA ligands. The increased absorption observed at a longer wavelength in (b) $(>1100 \mathrm{~nm})$ is attributed to parasitic absorption by the $\mathrm{Si}^{++} / \mathrm{SiO}_{2}$ wafer used as the substrate (see Methods). (c) The evolution of transfer characteristics and (d) the carrier trap density and subthreshold swing (SS) in PbS CQD-based TFTs at higher flashing energy densities $\left(3.25-4 \mathrm{~J} \mathrm{~cm}^{-2}\right)$. The lines are a guide to the eye.

$\mathrm{K}^{-1}$, then this yields a long-time average saturation temperature for the device of $23 \mathrm{~K}$ (i.e., $\Delta T \approx 100 \mathrm{~K}$ for the $\mathrm{PbS}$ CQD layer). Evidently, controlling the back-side cooling offers a method for tuning the annealing temperature within the device during FLA. Such an additional parameter could provide improved control over the processing temperature during FLA.

To understand why PbS CQD TFTs treated with $3.25 \mathrm{~J}$ $\mathrm{cm}^{-2}$ exhibit optimal electrical performance, we analyzed the surface topography of the CQD layers using atomic force microscopy (AFM) (Figure S6) and scanning electron microscopy (SEM) (Figure S7) measurements. No significant changes in the layer topography are observed in the topographical AFM images, as evidenced by the similarity in the root-mean-square (RMS) surface roughness of the different films (Figure S6). All layers contain voids that most likely form during solvent evaporation and drying. Similarly, the SEM images also fail to reveal any stark differences in the layer morphologies before and after FLA (Figure S7). Attempts to study the structural properties of the FLA PbS CQD layers using transmission electron microscopy (TEM) proved unsuccessful due to our inability to deposit the semiconductor and to perform FLA directly on the TEM grid. Despite that, the AFM and SEM results suggest that the improved electron mobility cannot be attributed to the morphological changes occurring within the $\mathrm{PbS} \mathrm{CQD}$ layers during FLA.

To gain further insight into the effect of FLA on the PbS CQDs, we studied the optical properties of the resulting films using spectroscopic ellipsometry. The measurements were conducted on similar $\mathrm{n}-\mathrm{Si}^{++} / \mathrm{SiO}_{2}$ wafers used to build the TFTs, so a comparison between optical and electrical measurements could be made. The refractive index $(n)$ of the films following FLA with a different optical energy density is shown in Figure 3a. The refractive index of the PbS CQD films with OA ligands significantly increases after MAI ligand exchange because of $\mathrm{OA}$ removal and film densification. Increasing the optical energy density increases the refractive index of the layers, which indicates suppression of organic residues within the layers. Importantly, the application of a short FLA step appears equally capable of removing organic residues as thermal annealing the sample for $30 \mathrm{~min}$. The measured reduction in organic residues is believed to be the primary reason for the increased electron mobility obtained at an optical energy density of $3.25 \mathrm{~J} \mathrm{~cm}^{-2}$. Similar observations have been reported previously for metal oxide nanoparticle TFTs using different post-deposition treatments. ${ }^{41,42}$

At this point, it is important to understand how rapid FLA results in an effective suppression of organic residues while concurrently preserving the low off-current in the channel. Figure $3 \mathrm{~b}$ displays the absorption spectra of the $\mathrm{PbS} C \mathrm{CQD}$ films before and after FLA with $3.25 \mathrm{~J} \mathrm{~cm}^{-2}$. The as-prepared $\mathrm{PbS}$ CQD films with OA ligands (inset in Figure $3 \mathrm{~b}$ ) exhibit a strong quantum confined excitonic peak at around $948 \mathrm{~nm}$. After ligand exchange with MAI, a red-shift of $\approx 50 \mathrm{~nm}$ in the excitonic peak is observed, indicating the successful replacement of OA ligands with atomic-sized iodide. The slightly increased absorption observed at longer wavelengths is attributed to parasitic absorption by the $\mathrm{Si}^{++} / \mathrm{SiO}_{2}$ substrate used for the ellipsometry measurements. Critically, the excitonic peak is still present with a negligible red-shift following FLA, which indicates preservation of quantum confinement. Additional supporting evidence comes from the photoluminescence (PL) measurements shown in Figure S8, where no significant changes in the PL spectra of PbS CQD layers can be observed before and after FLA with different optical energy densities. The results highlight the ability of 

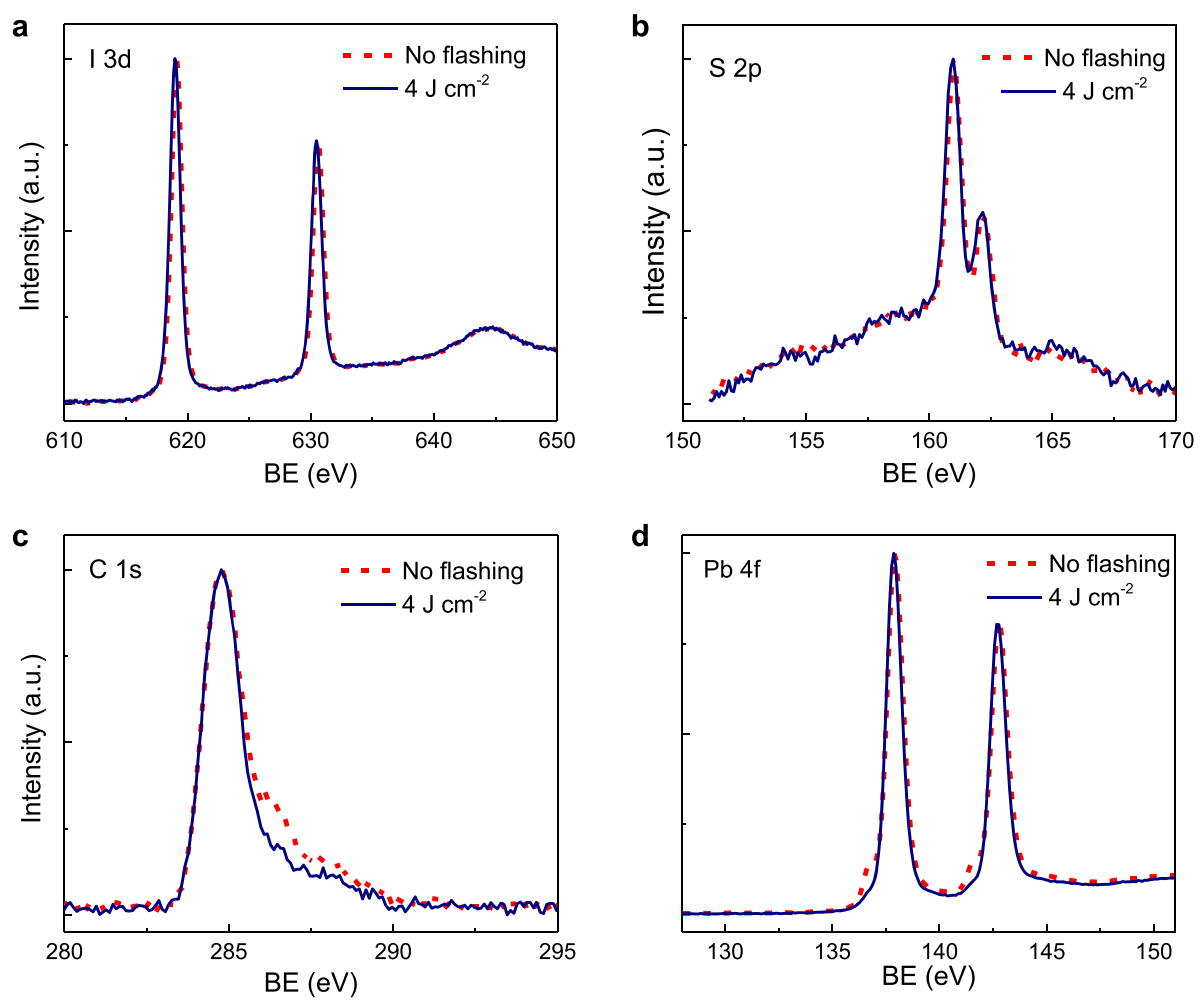

Figure 4. XPS spectra of (a) I 3d, (b) S 2p, (c) C 1s, and (d) Pb 4f chemical states before (red dashed line) and after FLA (dark blue line).

FLA to remove the organic residues from the CQD layer while preserving the low-dimensional nature of the system.

Figure $2 \mathrm{~b}$ shows that electron mobility in PbS CQD TFTs decreases upon FLA with energy densities $>3.25 \mathrm{~J} \mathrm{~cm}^{-2}$. To investigate the origin of this effect, we plotted the transfer characteristics of PbS CQD TFTs subjected to optical energy densities above this critical level (Figure 3c). We find that the subthreshold swing (SS) of the FLA-processed transistors increases when treated at $>3.25 \mathrm{~J} \mathrm{~cm}^{-2}$, accompanied by a larger operating hysteresis (Figure S4). The latter observation suggests the formation of excess trap states in the semiconducting channel. From these data, we were able to estimate the electron trap density $\left(N_{\text {traps }}\right)$ for each transistor using

$$
N_{\text {traps }}=\left(S S \frac{e}{k_{\mathrm{b}} T \ln 10}-1\right) \frac{C_{i}}{e}
$$

Here, $e, k_{\mathrm{b}}$, and $C_{i}$ are the elementary charge constant, Boltzmann constant, and dielectric capacitance, respectively.

Figure $3 \mathrm{~d}$ shows the calculated $N_{\text {traps }}$ versus the applied optical power density. The trap concentration increases with increasing optical energy density above $3.25 \mathrm{~J} \mathrm{~cm}^{-2}$, which may account for the mobility drop observed in Figure $2 \mathrm{~b}$. The evolution of $N_{\text {traps }}$ in TFTs treated with $<3.25 \mathrm{~J} \mathrm{~cm}^{-2}$ is shown in Figure S4. Evidently, the trap concentration reaches a minimum in PbS CQD TFTs treated with $3.25 \mathrm{~J} \mathrm{~cm}^{-2}$, which agrees with the highest electron mobility achieved. The higher $N_{\text {traps }}$ measured at $<3.25 \mathrm{~J} \mathrm{~cm}^{-2}$ is most likely the result of interaction between organic residues and injected electrons in the channel. ${ }^{43}$ Based on these results, we conclude that FLA with a xenon flash lamp can be used to reduce $N_{\text {traps }}$ and improve long-range charge transport across the $\mathrm{PbS}$ CQD channel.

Another extrinsic effect that could account for the electron mobility drop seen upon high optical energy treatment is the change in the stoichiometry of the $\mathrm{PbS}$ CQDs. Figure $3 \mathrm{c}$ presents the transfer characteristics of $\mathrm{PbS}$ CQD transistors, which reveal a systematic shift toward more positive $V_{G}$ with increasing optical energy density. The latter indicates a systematic reduction in the carrier concentration in the channel. To rationalize this observation, we performed X-ray photoelectron spectroscopy (XPS) measurements on $\mathrm{PbS}$ CQD films before and after FLA. Iodide-capped $\mathrm{PbS}$ CQD films exhibit two iodide (I $3 \mathrm{~d}_{3 / 2}$ and $3 \mathrm{~d}_{5 / 2}$ ) and sulfur core levels ( $S 2 p_{3 / 2}$ and $2 p_{5 / 2}$ ), as shown in Figure $4 a$,b. No significant change in the XPS spectra of the core levels is observed upon flashing, indicating that the iodide and sulfur compounds remain unaffected. On the other hand, the intensity of carbon core levels (C 1s) decreases following FLA (Figure 4c), suggesting a reduction in the concentration of organic residues.

The XPS measurements also reveal two chemical states of $\mathrm{Pb}$ core levels with two additional shoulders (Figure 4d). These two shoulders originate from undercharged $\mathrm{Pb}$, which can be the source of electron trap states. ${ }^{44,45}$ Photonic treatment of the $\mathrm{PbS} \mathrm{CQD}$ layers reduces the intensity of the shoulders (Figure S9), which may account for the improvement in electron mobility observed in TFTs treated with $3.25 \mathrm{~J} \mathrm{~cm}^{-2}$. Subjecting the $\mathrm{PbS} \mathrm{CQD}$ layer to a light pulse intensity of $>3.25 \mathrm{~J} \mathrm{~cm}^{-2}$ dramatically reduces the intensity of these shoulders, an effect most likely related to further ablation of $\mathrm{Pb}$ atoms from the surface of the $\mathrm{PbS}$ CQDs. If true, such a process is expected to result in a $\mathrm{Pb}$ deficient $\mathrm{PbS}$ CQD surface, a hypothesis supported by energydispersive spectroscopy (EDS) measurements shown in Figure S10. To this end, it has been previously shown that in the case of PbS CQDs, a Pb-rich surface results in n-type conduction. ${ }^{46}$ Thus, reducing the $\mathrm{Pb}$ concentration is expected to alter the electronic properties of $\mathrm{PbS} C Q \mathrm{Ds}$ with adverse effects on 
a

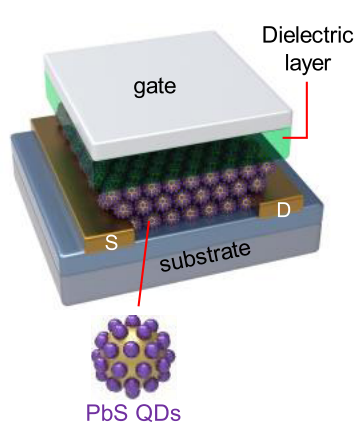

C

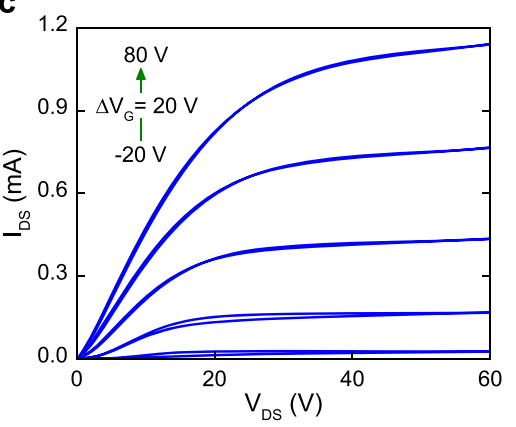

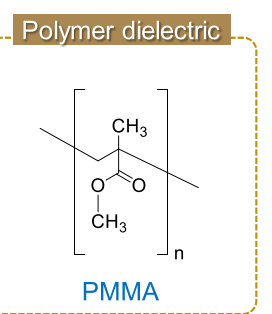

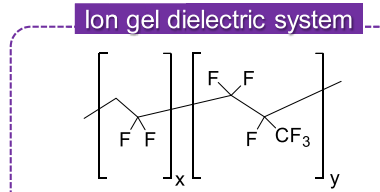

PVDF-HFP

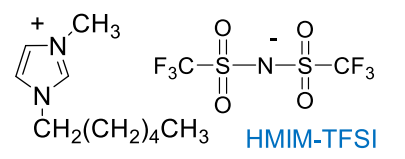

d

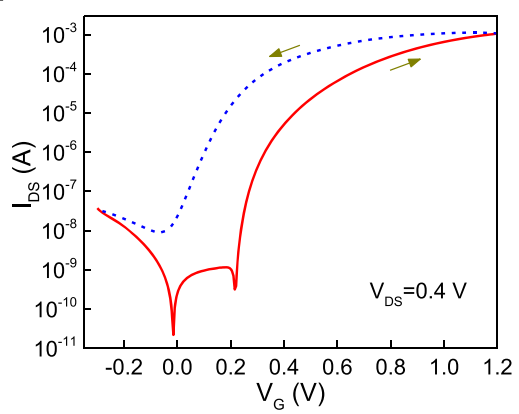

b

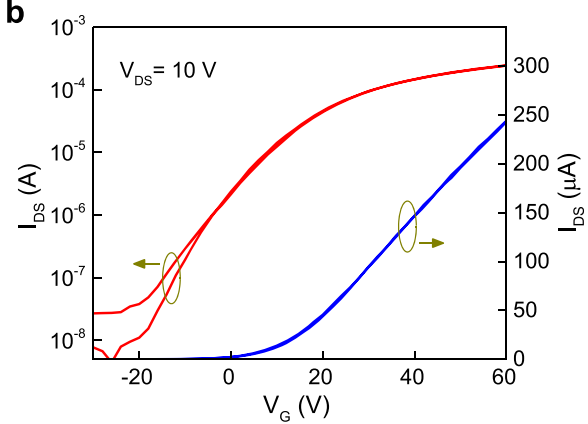

e

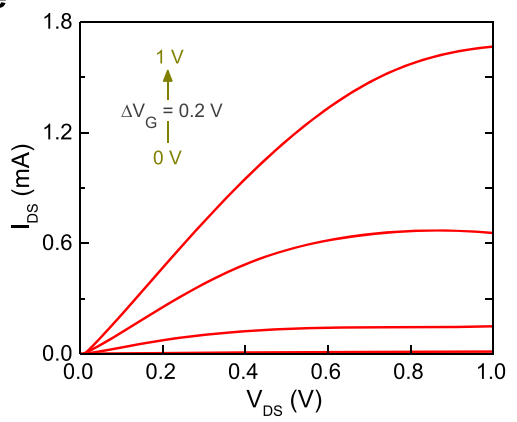

Figure 5. (a) Three-dimensional (3D) schematic illustration of top-gate PbS CQD TFTs prepared by FLA utilizing PMMA and ion gel as the gate dielectrics. (b) Transfer and (c) output characteristics of PbS CQD TFTs with PMMA gate dielectric. (d) Transfer and (e) output characteristics of $\mathrm{PbS}$ CQD TFTs with the ion-gel gate dielectric. The geometric capacitance of the ion-gel gate dielectric and the linear fitting used to calculate the electron mobility are shown in Figures S11.

electron transport, which is experimentally seen in Figures $2 b$ and 3c. Creation of dangling bonds on the PbS CQD's surface, occurring upon $\mathrm{Pb}$ ablation, could act as scattering sites and lead to increased trapping, which could in turn explain both the increasing SS (Figure 3c,d) and mobility degradation (Figure 2b) upon exposure to high-energy-density light pulses. Based on the experimental findings presented so far, we conclude that $\mathrm{PbS} \mathrm{CQD}$ layers subjected to optical energy densities below $3.25 \mathrm{~J} \mathrm{~cm}^{-2}$ lead to higher trap concentrations and degraded electron transport, primarily due to the presence of organic residues (i.e., $\mathrm{MA}^{+}$and $\mathrm{OA}^{-}$). Exposing the $\mathrm{PbS}$ $\mathrm{CQD}$ to $>3.25 \mathrm{~J} \mathrm{~cm}^{-2}$ results in the ablation of $\mathrm{Pb}$ atoms from the surface of the quantum dots, resulting again in reduced electron transport in line with previous reports. ${ }^{46}$ Thus, balancing the influence of these two limiting processes yields transistor with optimal operation, which for $\mathrm{PbS}$ CQDs appears to take place for a light energy density of $3.25 \mathrm{~J} \mathrm{~cm}^{-2}$.

The device data presented and analyzed so far were obtained from BG-TC PbS CQD transistors utilizing $\mathrm{SiO}_{2}$ as the gate dielectric, which is known to exhibit a large concentration of surface trap states due to the existence of dangling bonds and its generally more natural surface. ${ }^{2,4}$ Since TFTs are interfacial devices, the charge carrier transport dynamics in the channel are strongly influenced by the properties of the dielectric/ semiconductor interface. In an effort to reduce the adverse effects of interface trapping, we fabricated top-gate, bottomcontact (TG-BC) TFTs using a polymer gate dielectric, namely, PMMA (Figure 5a). The top-gate TFT architecture allows conformal coating of the solution-deposited polymer dielectric directly onto the $\mathrm{PbS}$ CQD channel, which has been shown to enhance the coupling between the gate field and the channel, compared to bottom-gate TFTs. ${ }^{41,42}$ As expected, PMMA-based PbS CQD TFTs exhibit a strong n-channel character with good current modulation characteristics, good saturation, and, unlike $\mathrm{SiO}_{2}$-based devices, negligible operational hysteresis (Figure $5 \mathrm{~b}, \mathrm{c}$ ). The improved $\mathrm{PbS} \mathrm{CQD} /$ PMMA channel interface results in a higher electron mobility value of $0.48 \mathrm{~cm}^{2} \mathrm{~V}^{-1} \mathrm{~s}^{-1}$, most likely a direct result of the improved dielectric/channel interface due to the reduced interfacial traps concentration.

Despite the improved electron mobility, the operating voltage of the PMMA-based PbS CQD TFTs remains high, in the range of -40 to $60 \mathrm{~V}$, due to the low dielectric permittivity of PMMA $(\approx 3.0)$ (Figure $5 \mathrm{~b}, \mathrm{c})$. To address this issue, we fabricated TG-BC transistors using a solutionprocessed ion-gel gate dielectric composed of an ionic liquid and poly(vinylidene fluoride)-hexafluoropropylene (PVDFHFP) mixture (Figure 5a). The high geometrical capacitance $\left(>1 \mu \mathrm{F} / \mathrm{cm}^{2}\right.$; see Figure S11) of the ion-gel dielectric ${ }^{47}$ results in a dramatic reduction in the TFT's operating voltage to -0.3 to $1.2 \mathrm{~V}$ (Figure 5d). Besides, devices exhibit a high channel current on/off ratio of $10^{6}$, a high electron mobility value of $3.74 \mathrm{~cm}^{2} \mathrm{~V}^{-1} \mathrm{~s}^{-1}$ (calculated using the experimentally measured geometrical capacitance-at $40 \mathrm{~Hz}$-of the dielectric and the linear fit shown in Figure S11), and good channel current saturation (Figure 5e). The notable electron mobility increase is most likely attributed to screening of electron traps by the excess number of electrons induced by the gate field due to the enhanced capacitive coupling between the gate and the transistor channel in agreement with previous studies. $^{2,23}$

To put the aforementioned transistor performance metrics into prospective, we have attempted to compare key device characteristics, namely, dielectric material, channel current on/ off ratio, and electron mobility, extracted from our photonically processed $\mathrm{PbS} C \mathrm{CQD}$ transistors, with previously reported data for $\mathrm{PbS}$ transistors (Figure 6). Evidently, FLA enables the development of PbS CQD TFTs with operating characteristics 


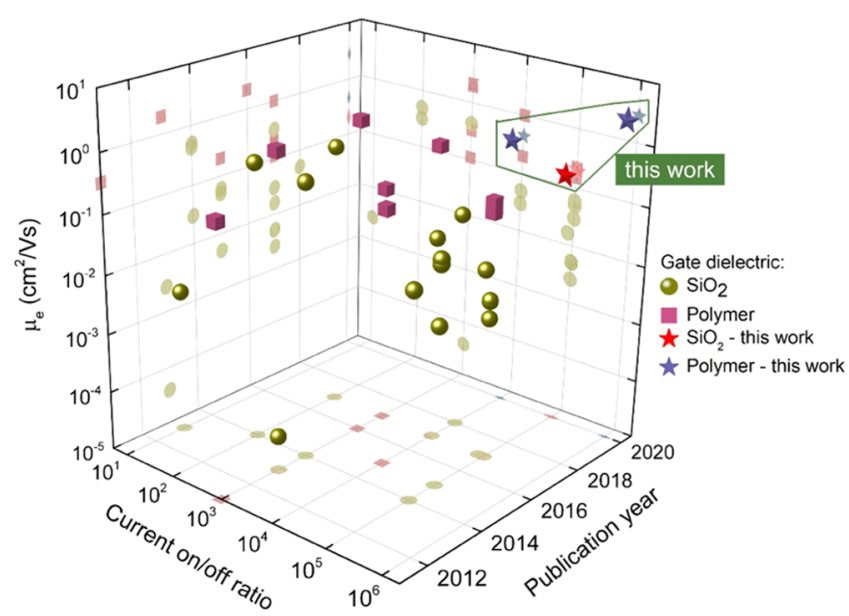

Figure 6. Comparison of electron mobility $\left(\mu_{\mathrm{e}}\right)$ and channel current on/off ratio reported for PbS QD TFTs based on different gate dielectrics during the past 10 years. ${ }^{2,4,21,26,27,30,48-55}$ The projection of each data point on the $2 \mathrm{D}$ plane of $\mu_{\mathrm{e}}$, current on/off ratio, and publication year are also shown in their corresponding colors.

on par with, if not better than, state-of-the-art devices reported previously. Besides performance, FLA offers the ability for rapid thermal processing of $\mathrm{PbS} C \mathrm{CQDs}$ while maintaining their low dimensionality, which could potentially enable its use to other device applications and material systems, including higher-electron-mobility CQDs such as those based on PbSe.

\section{CONCLUSIONS}

In conclusion, we have reported on the application of flash lamp annealing for post-deposition treatment of $\mathrm{PbS}$ CQDs in the millisecond time scale using a xenon flash lamp. The method is rapid, simple, highly scalable, and allows for efficient sintering of $\mathrm{PbS} \mathrm{CQD}$ layers without compromising the quantum confinement of the dots, while simultaneously reducing the organic residues (insulating ligands, etc.) in the layer. Transistors based on photonically processed $\mathrm{PbS} C \mathrm{CQD}$ layers exhibit a maximum electron mobility of $0.2 \mathrm{~cm}^{2} \mathrm{~V}^{-1} \mathrm{~s}^{-1}$, a value significantly higher than that obtained for control devices prepared via conventional thermal annealing. Combining the FLA $\mathrm{PbS}$ CQDs with polymeric and ion-gel gate dielectrics results in transistors with even higher electron mobilities of 0.48 and $3.74 \mathrm{~cm}^{2} \mathrm{~V}^{-1} \mathrm{~s}^{-1}$, respectively, bringing the performance of our devices on par with the current stateof-the-art $\mathrm{PbS} \mathrm{CQD}$ transistors. The present work highlights the tremendous potential of FLA for the rapid post-deposition processing of $\mathrm{PbS} \mathrm{CQDs}$ and their application in large-area electronics. To this end, the method provides a simple and highly scalable alternative to traditional thermal annealing and could be extended to other material systems (e.g., PbSe, CdSe/ $\mathrm{ZnS}$ ) and devices, a few examples of which include lightemitting diodes, solar cells, photodetectors, and thermoelectrics.

\section{METHODS}

Material and TFT Preparation. As substrates, n-doped $\mathrm{Si}^{++} / \mathrm{SiO}_{2}$ with lithographically patterned interdigitated ITO/Au $(10 / 30 \mathrm{~nm})$ electrodes were used. The thickness of the $\mathrm{SiO}_{2}$ gate dielectric was $230 \mathrm{~nm}$ with channel length and width of $20 \mu \mathrm{m}$ and $1 \mathrm{~cm}$, respectively. CQDs $(\approx 3 \mathrm{~nm}$ in diameter) were synthesized following previously reported methods. ${ }^{56}$ In brief, $0.18 \mathrm{~g}(1 \mathrm{~mol})$ of bis (trimethylsilyl)sulfide (TMS) was added to $10 \mathrm{~mL}$ of 1-octadecene
(ODE) that had been dried and degassed by heating to $80{ }^{\circ} \mathrm{C}$ under vacuum for $24 \mathrm{~h}$. A mixture of $\mathrm{OA}(1.34 \mathrm{~g}, 4.8 \mathrm{mmol}), \mathrm{PbO}(0.45 \mathrm{~g}$, $2.0 \mathrm{mmol})$, and $\operatorname{ODE}(14.2 \mathrm{~g}, 56.2 \mathrm{mmol})$ was heated to $95{ }^{\circ} \mathrm{C}$ under vacuum for $16 \mathrm{~h}$ and placed under Ar gas. The flask temperature was increased to $120^{\circ} \mathrm{C}$, and the TMS/ODE mixture was injected. After injection, the flask was allowed to cool gradually to $35^{\circ} \mathrm{C}$. The CQDs were precipitated using distilled acetone $(50 \mathrm{~mL})$ and centrifuged. The supernatant was discarded, and the precipitate was redispersed in toluene. The CQDs were precipitated again using methanol $(20 \mathrm{~mL})$, centrifuged $(5 \mathrm{~min})$, dried, dispersed in octane $\left(50 \mathrm{mg} \mathrm{mL}^{-1}\right)$, and transported into a nitrogen glovebox (oxygen below $2 \mathrm{ppm}$ and moisture below $10 \mathrm{ppm}$ ). The CQD film deposition and ligand exchange (LE) were performed using a layer-by-layer (LbL) sequential method. The first thin semiconducting layer was deposited by spin-casting $2 \mathrm{mg} / \mathrm{mL}$ of the CQD solution in hexane at $1000 \mathrm{rpm}$ for $30 \mathrm{~s}$. The LE process was done by soaking the OA-capped CQD films in a $20 \mathrm{mM}$ methanol solution of methylammonium iodide (MAI) for $30 \mathrm{~s}$ before then being spin-dried at $1000 \mathrm{rpm}$ for $30 \mathrm{~s}$. Two washing steps with pure methanol were used to remove ligand excesses for $10 \mathrm{~s}$. The films were then spin-dried at $1000 \mathrm{rpm}$ for $30 \mathrm{~s}$. Another two thicker CQD films were formed by spin-casting $20 \mathrm{mg} /$ $\mathrm{mL}$ of the CQD solution in hexane at $1500 \mathrm{rpm}$ for $30 \mathrm{~s}$. The LE process was conducted following a similar procedure to that described above. All of the processes were performed in a $\mathrm{N}_{2}$-filled glovebox. The final thickness of the deposited CQD films was $\approx 60 \mathrm{~nm}$, as revealed by ellipsometry measurement. For the FLA process, the devices were put inside an isolated chamber to avoid ambient air exposure before they were then placed inside the FLA chamber. The devices were exposed with $300 \mu$ s pulse light from a xenon lamp with energy densities ranging from 2.2 to $4 \mathrm{~J} \mathrm{~cm}^{-2}$. Top polymer gate dielectric films were deposited after performing FLA on CQD films. PMMA films were deposited by spin-coating $50 \mathrm{mg} / \mathrm{mL}$ of PMMA solution in ethyl acetate at $3000 \mathrm{rpm}$ for $40 \mathrm{~s}$. Ion-gel formulation was prepared by first dissolving poly(vinylidene fluoride)-co-hexafluoropropylene (PVDF-HFP) in N,N-dimethylformamide (DMF, $80 \mathrm{mg} /$ $\mathrm{mL}$ ) and leaving the solution under stirring at $80^{\circ} \mathrm{C}$ for at least $3 \mathrm{~h}$. An ionic liquid based on 1-hexyl-3-methylimidazolium bis(trifluormethylsulfonyl)imide (HMIM-TFSI) was mixed with the DMF solution of PVDF-HFP with a weight ratio of 1:4 (HMIMTFSI/PVDF-HFP). The ion-gel solution was spin-coated at $1000 \mathrm{rpm}$ for $60 \mathrm{~s}$. The polymer gate dielectric films were then subjected to thermal annealing at $95{ }^{\circ} \mathrm{C}$ to remove residual solvents. Finally, aluminum and gold $(100 \mathrm{~nm})$ were evaporated as gate electrode on top of PMMA and ion-gel films, respectively.

Optothermal Simulations. A transfer matrix method (developed in-house) was used to model light propagation and absorption distribution within the device. A finite element method (COMSOL Multiphysics) was used to model heat dissipation (conduction and convection) and extract the temperature transients in the device stack.

Film Characterization. The electrical characteristics of the TFT devices were measured using a Keysight B2912A precision/measure unit connected to a probe station in a glovebox. The electron mobility of the devices in the linear regime was estimated using gradual channel approximation (eq 1). The film thickness was measured using a Tencor profilometer. The optical constants (refractive index and extinction coefficient) for the CQD films were collected by variableangle spectroscopic ellipsometry (VASE) with an M-2000 ellipsometer (J.A. Woolam Co., Inc). All VASE measurements were performed on $\mathrm{PbS}$ CQD films spin-cast atop $\mathrm{Si}^{++}(500 \mu \mathrm{m}) / \mathrm{SiO}_{2}(50$ $\mathrm{nm}$ ), with the incident angle being varied from 50 to $80^{\circ}$ in $5^{\circ}$ steps relative to the sample. The software CompleteEASE (J.A. Woolam Co., Inc.) was used to process all collected data, and the optical constants were inferred from the B-splines model. The morphology of the CQD films was measured using atomic force microscopy (Solver Next SPM from NT-MDT) and SEM (Carl Zeiss Auriga with EDS Bruker Nano XFlash Detector 410-M). The XPS measurements were performed on a Kratos Axis Supra instrument equipped with a monochromatic $\mathrm{Al} \mathrm{K} \alpha \mathrm{X}$-ray source $(h \nu=1486.6 \mathrm{eV})$ operated at a power of $150 \mathrm{~W}$ and under UHV conditions in the range of $\approx 10^{-9}$ mbar. All spectra were recorded in hybrid mode using electrostatic 
and magnetic lenses and an aperture slot of $300 \mu \mathrm{m} \times 700 \mu \mathrm{m}$. The survey and high-resolution spectra were acquired at fixed analyzer pass energies of 80 and $20 \mathrm{eV}$, respectively. The samples were mounted in floating mode to avoid differential charging. Therefore, XPS spectra were acquired using charge neutralization.

\section{ASSOCIATED CONTENT}

\section{SI Supporting Information}

The Supporting Information is available free of charge at https://pubs.acs.org/doi/10.1021/acsami.0c06306.

Spectroscopic ellipsometry measurements, operating characteristics of thermally annealed transistor, electron trap analysis, coupled optothermal simulations of FLA $\mathrm{PbS}$ QDs transistors, atomic force measurements, SEM measurements, photoluminescence measurements, XPS measurements, energy-dispersive X-ray spectroscopy (EDX) analysis of FLA samples, and capacitancefrequency analysis of the gate dielectric (Figures S1S11) (PDF)

\section{AUTHOR INFORMATION}

\section{Corresponding Authors}

Mohamad I. Nugraha - Physical Sciences and Engineering Division (PSE), KAUST Solar Center (KSC), King Abdullah

University of Science and Technology (KAUST), Thuwal 23955-6900, Saudi Arabia; Email: mohamad.nugraha@ kaust.edu.sa

Thomas D. Anthopoulos - Physical Sciences and Engineering Division (PSE), KAUST Solar Center (KSC), King Abdullah University of Science and Technology (KAUST), Thuwal 23955-6900, Saudi Arabia; ○ orcid.org/0000-0002-09788813; Email: thomas.anthopoulos@kaust.edu.sa

\section{Authors}

Emre Yarali - Physical Sciences and Engineering Division (PSE), KAUST Solar Center (KSC), King Abdullah University of Science and Technology (KAUST), Thuwal 23955-6900, Saudi Arabia

Yuliar Firdaus - Physical Sciences and Engineering Division (PSE), KAUST Solar Center (KSC), King Abdullah University of Science and Technology (KAUST), Thuwal 23955-6900, Saudi Arabia

Yuanbao Lin - Physical Sciences and Engineering Division (PSE), KAUST Solar Center (KSC), King Abdullah University of Science and Technology (KAUST), Thuwal 23955-6900, Saudi Arabia

Abdulrahman El-Labban - Physical Sciences and Engineering Division (PSE), KAUST Solar Center (KSC), King Abdullah University of Science and Technology (KAUST), Thuwal 23955-6900, Saudi Arabia

Murali Gedda - Physical Sciences and Engineering Division (PSE), KAUST Solar Center (KSC), King Abdullah University of Science and Technology (KAUST), Thuwal 23955-6900, Saudi Arabia

Elefterios Lidorikis - Department of Materials Science and Engineering, University of Ioannina, Ioannina 45110, Greece

Emre Yengel - Physical Sciences and Engineering Division (PSE), KAUST Solar Center (KSC), King Abdullah University of Science and Technology (KAUST), Thuwal 23955-6900, Saudi Arabia; (1) orcid.org/0000-0001-7208-4803

Hendrik Faber - Physical Sciences and Engineering Division (PSE), KAUST Solar Center (KSC), King Abdullah University of Science and Technology (KAUST), Thuwal 23955-6900, Saudi Arabia

Complete contact information is available at: https://pubs.acs.org/10.1021/acsami.0c06306

\section{Notes}

The authors declare no competing financial interest.

\section{ACKNOWLEDGMENTS}

This publication is based upon work supported by the King Abdullah University of Science and Technology (KAUST) Office of Sponsored Research (OSR) under Award No: OSR2018-CARF/CCF-3079. The authors would like to acknowledge N. Wehbe at KAUST Core Labs for supporting the XPS measurements.

\section{REFERENCES}

(1) Kim, D. K.; Lai, Y.; Diroll, B. T.; Murray, C. B.; Kagan, C. R. Flexible and Low-Voltage Integrated Circuits Constructed from HighPerformance Nanocrystal Transistors. Nat. Commun. 2012, 3, No. 1216.

(2) Nugraha, M. I.; Häusermann, R.; Bisri, S. Z.; Matsui, H.; Sytnyk, M.; Heiss, W.; Takeya, J.; Loi, M. A. High Mobility and Low Density of Trap States in Dual-Solid-Gated PbS Nanocrystal Field-Effect Transistors. Adv. Mater. 2015, 27, 2107-2112.

(3) Kim, D. K.; Lai, Y.; Vemulkar, T. R.; Kagan, C. R. Flexible, LowVoltage, and Low-Hysteresis PbSe Nanowire Field-Effect Transistors. ACS Nano 2011, 5, 10074-10083.

(4) Nugraha, M. I.; Häusermann, R.; Watanabe, S.; Matsui, H.; Sytnyk, M.; Heiss, W.; Takeya, J.; Loi, M. A. Broadening of Distribution of Trap States in PbS Quantum Dot Field-Effect Transistors with High-k Dielectrics. ACS Appl. Mater. Interfaces 2017, 9, 4719-4724.

(5) Gong, X.; Yang, Z.; Walters, G.; Comin, R.; Ning, Z.; Beauregard, E.; Adinolfi, V.; Voznyy, O.; Sargent, E. H. Highly Efficient Quantum Dot Near-Infrared Light-Emitting Diodes. Nat. Photonics 2016, 10, 253-257.

(6) Sun, L.; Choi, J. J.; Stachnik, D.; Bartnik, A. C.; Hyun, B.-R.; Malliaras, G. G.; Hanrath, T.; Wise, F. W. Bright Infrared QuantumDot Light-Emitting Diodes through Inter-Dot Spacing Control. Nat. Nanotechnol. 2012, 7, 369-373.

(7) Dai, M. Q.; Yung, L. Y. L. Ethylenediamine-Assisted Ligand Exchange and Phase Transfer of Oleophilic Quantum Dots: Stripping of Original Ligands and Preservation of Photoluminescence. Chem. Mater. 2013, 25, 2193-2201.

(8) Mashford, B. S.; Stevenson, M.; Popovic, Z.; Hamilton, C.; Zhou, Z.; Breen, C.; Steckel, J.; Bulovic, V.; Bawendi, M.; CoeSullivan, S.; Kazlas, P. T. High-Efficiency Quantum-Dot LightEmitting Devices with Enhanced Charge Injection. Nat. Photonics 2013, 7, 407-412.

(9) Schornbaum, J.; Zakharko, Y.; Held, M.; Thiemann, S.; Gannott, F.; Zaumseil, J. Light-Emitting Quantum Dot Transistors: Emission at High Charge Carrier Densities. Nano Lett. 2015, 15, 1822-1828.

(10) Ip, A. H.; Thon, S. M.; Hoogland, S.; Voznyy, O.; Zhitomirsky, D.; Debnath, R.; Levina, L.; Rollny, L. R.; Carey, G. H.; Fischer, A.; Kemp, K. W.; Kramer, I. J.; Ning, Z.; Labelle, A. J.; Chou, K. W.; Amassian, A.; Sargent, E. H. Hybrid Passivated Colloidal Quantum Dot Solids. Nat. Nanotechnol. 2012, 7, 577-582.

(11) Ning, Z.; Voznyy, O.; Pan, J.; Hoogland, S.; Adinolfi, V.; Xu, J.; Li, M.; Kirmani, A. R.; Sun, J.; Minor, J.; Kemp, K. W.; Dong, H.; Rollny, L.; Labelle, A.; Carey, G.; Sutherland, B.; Hill, I.; Amassian, A.; Liu, H.; Tang, J.; Bakr, O. M.; Sargent, E. H. Air-Stable n-Type Colloidal Quantum Dot Solids. Nat. Mater. 2014, 13, 822-828.

(12) Piliego, C.; Protesescu, L.; Bisri, S. Z.; Kovalenko, M. V.; Loi, M. A. 5.2\% Efficient PbS Nanocrystal Schottky Solar Cells. Energy Environ. Sci. 2013, 6, 3054. 
(13) Brown, P. R.; Kim, D.; Lunt, R. R.; Zhao, N.; Bawendi, M. G.; Grossman, J. C.; Bulović, V. Energy Level Modification in Lead Sulfide Quantum Dot Thin Films through Ligand Exchange. ACS Nano 2014, 8, 5863-5872.

(14) Wang, R. Y.; Feser, J. P.; Lee, J. S.; Talapin, D. V.; Segalman, R.; Majumdar, A. Enhanced Thermopower in PbSe Nanocrystal Quantum Dot Superlattices. Nano Lett. 2008, 8, 2283-2288.

(15) Ibáñez, M.; Luo, Z.; Genç, A.; Piveteau, L.; Ortega, S.; Cadavid, D.; Dobrozhan, O.; Liu, Y.; Nachtegaal, M.; Zebarjadi, M.; Arbiol, J.; Kovalenko, M. V.; Cabot, A. High-Performance Thermoelectric Nanocomposites from Nanocrystal Building Blocks. Nat. Commun. 2016, 7, No. 10766.

(16) Nugraha, M. I.; Kim, H.; Sun, B.; Haque, M. A.; de Arquer, F. P. G.; Villalva, D. R.; El-Labban, A.; Sargent, E. H.; Alshareef, H. N.; Baran, D. Low-Temperature-Processed Colloidal Quantum Dots as Building Blocks for Thermoelectrics. Adv. Energy Mater 2019, No. 1803049.

(17) Han, C.; Tan, G.; Varghese, T.; Kanatzidis, M. G.; Zhang, Y. High-Performance PbTe Thermoelectric Films by Scalable and LowCost Printing. ACS Energy Lett. 2018, 3, 818-822.

(18) Thon, S. M.; Ip, A. H.; Voznyy, O.; Levina, L.; Kemp, K. W.; Carey, G. H.; Masala, S.; Sargent, E. H. Role of Bond Adaptability in the Passivation of Colloidal Quantum Dot Solids. ACS Nano 2013, 7, $7680-7688$.

(19) Kramer, I. J.; Minor, J. C.; Moreno-Bautista, G.; Rollny, L.; Kanjanaboos, P.; Kopilovic, D.; Thon, S. M.; Carey, G. H.; Chou, K. W.; Zhitomirsky, D.; Amassian, A.; Sargent, E. H. Efficient SprayCoated Colloidal Quantum Dot Solar Cells. Adv. Mater. 2015, 27, $116-121$.

(20) Choi, H.; Lee, J. G.; Mai, X. D.; Beard, M. C.; Yoon, S. S.; Jeong, S. Supersonically Spray-Coated Colloidal Quantum Dot Ink Solar Cells. Sci. Rep. 2017, 7, No. 622.

(21) Balazs, D. M.; Nugraha, M. I.; Bisri, S. Z.; Sytnyk, M.; Heiss, W.; Loi, M. A. Reducing Charge Trapping in PbS Colloidal Quantum Dot Solids. Appl. Phys. Lett. 2014, 104, No. 112104.

(22) Jung, S. M.; Kang, H. L.; Won, J. K.; Kim, J.; Hwang, C.; Ahn, K.; Chung, I.; Ju, B. K.; Kim, M. G.; Park, S. K. High-Performance Quantum Dot Thin-Film Transistors with Environmentally Benign Surface Functionalization and Robust Defect Passivation. ACS Appl. Mater. Interfaces 2018, 10, 3739-3749.

(23) Shulga, A. G.; Piveteau, L.; Bisri, S. Z.; Kovalenko, M. V.; Loi, M. A. Double Gate PbS Quantum Dot Field-Effect Transistors for Tuneable Electrical Characteristics. Adv. Electron. Mater. 2016, 2, No. 1500467.

(24) Son, J. S.; Choi, M. K.; Han, M. K.; Park, K.; Kim, J. Y.; Lim, S. J.; Oh, M.; Kuk, Y.; Park, C.; Kim, S. J.; Hyeon, T. N-Type Nanostructured Thermoelectric Materials Prepared from Chemically Synthesized Ultrathin $\mathrm{Bi}_{2} \mathrm{Te}_{3}$ Nanoplates. Nano Lett. 2012, 12, 640647.

(25) Lu, K.; Wang, Y.; Liu, Z.; Han, L.; Shi, G.; Fang, H.; Chen, J.; Ye, X.; Chen, S.; Yang, F.; Shulga, A. G.; Wu, T.; Gu, M.; Zhou, S.; Fan, J.; Loi, M. A.; Ma, W. High-Efficiency PbS Quantum-Dot Solar Cells with Greatly Simplified Fabrication Processing via "SolventCuring. Adv. Mater. 2018, 30, No. 1707572.

(26) Balazs, D. M.; Dirin, D. N.; Fang, H. H.; Protesescu, L.; Ten Brink, G. H.; Kooi, B. J.; Kovalenko, M. V.; Loi, M. A. CounterionMediated Ligand Exchange for PbS Colloidal Quantum Dot Superlattices. ACS Nano 2015, 9, 11951-11959.

(27) Jo, C. H.; Kim, J. H.; Kim, J.; Kim, J.; Oh, M. S.; Kang, M. S.; Kim, M.; Kim, Y.; Ju, B.; Park, S. K. Low-Temperature Annealed PbS Quantum Dot Films for Scalable and Flexible Ambipolar Thin-FilmTransistors and Circuits†. J. Mater. Chem. C 2014, 2, 10305-10311. (28) Law, M.; Luther, J. M.; Song, Q.; Hughes, B. K.; Perkins, C. L.; Nozik, A. J. Structural, Optical, and Electrical Properties of PbSe Nanocrystal Solids Treated Thermally or with Simple Amines. J. Am. Chem. Soc. 2008, 130, 5974-5985.

(29) Lee, J.-S.; Kovalenko, M. V.; Huang, J.; Chung, D. S.; Talapin, D. V. Band-like Transport, High Electron Mobility and High
Photoconductivity in All-Inorganic Nanocrystal Arrays. Nat. Nanotechnol. 2011, 6, 348-352.

(30) Nugraha, M. I.; Kumagai, S.; Watanabe, S.; Sytnyk, M.; Heiss, W.; Loi, M. A.; Takeya, J. Enabling Ambipolar to Heavy N-Type Transport in PbS Quantum Dot Solids through Doping with Organic Molecules. ACS Appl. Mater. Interfaces 2017, 9, 18039-18045.

(31) Sun, B.; Voznyy, O.; Tan, H.; Stadler, P.; Liu, M.; Walters, G.; Proppe, A. H.; Liu, M.; Fan, J.; Zhuang, T.; Li, J.; Wei, M.; Xu, J.; Kim, Y.; Hoogland, S.; Sargent, E. H. Pseudohalide-Exchanged Quantum Dot Solids Achieve Record Quantum Efficiency in Infrared Photovoltaics. Adv. Mater. 2017, 29, No. 1700749.

(32) Yarali, E.; Koutsiaki, C.; Faber, H.; Tetzner, K.; Yengel, E.; Patsalas, P.; Kalfagiannis, N.; Koutsogeorgis, D. C.; Anthopoulos, T. D. Recent Progress in Photonic Processing of Metal-Oxide Transistors. Adv. Funct. Mater. 2020, 30, No. 1906022.

(33) Garlapati, S. K.; Divya, M.; Breitung, B.; Kruk, R.; Hahn, H.; Dasgupta, S. Printed Electronics Based on Inorganic Semiconductors: From Processes and Materials to Devices. Adv. Mater. 2018, 30, No. 1707600.

(34) Kim, R. H.; Leem, J.; Muratore, C.; Nam, S.; Rao, R.; Jawaid, A.; Durstock, M.; McConney, M.; Drummy, L.; Rai, R.; Voevodin, A.; Glavin, N. Photonic Crystallization of Two-Dimensional $\mathrm{MoS}_{2}$ for Stretchable Photodetectors. Nanoscale 2019, 11, 13260-13268.

(35) Daunis, T. B.; Schroder, K. A.; Hsu, J. W. P. Photonic Curing of Solution-Deposited $\mathrm{ZrO} 2$ Dielectric on PEN: A Path towards HighThroughput Processing of Oxide Electronics. npj Flexible Electron. 2020, 4, No. 7

(36) Garlapati, S. K.; Gebauer, J. S.; Dehm, S.; Bruns, M.; Winterer, M.; Hahn, H.; Dasgupta, S. Room-Temperature Processing of Printed Oxide FETs Using Ultraviolet Photonic Curing. Adv. Electron. Mater. 2017, 3, No. 1600476.

(37) Garlapati, S. K.; Marques, G. C.; Gebauer, J. S.; Dehm, S.; Bruns, M.; Winterer, M.; Tahoori, M. B.; Aghassi-Hagmann, J.; Hahn, H.; Dasgupta, S. High Performance Printed Oxide Field-Effect Transistors Processed Using Photonic Curing. Nanotechnology 2018, 29, No. 235205.

(38) Gao, Y.; Dong, Y.; Huang, K.; Zhang, C.; Liu, B.; Wang, S.; Shi, J.; Xie, H.; Huang, H.; Xiao, S.; He, J.; Gao, Y.; Hatton, R. A.; Yang, J. Highly Efficient, Solution-Processed $\mathrm{CsPbI}_{2} \mathrm{Br}$ Planar Heterojunction Perovskite Solar Cells via Flash Annealing. ACS Photonics 2018, 5, 4104-4110.

(39) Moon, C. J.; Kim, H. S. Intense Pulsed Light Annealing Process of Indium-Gallium-Zinc-Oxide Semiconductors via Flash White Light Combined with Deep-UV and Near-Infrared Drying for HighPerformance Thin-Film Transistors. ACS Appl. Mater. Interfaces 2019, 11, 13380-13388

(40) Nugraha, M. I.; Kim, H.; Sun, B.; Desai, S.; de Arquer, F. P. G.; Sargent, E. H.; Alshareef, H. N.; Baran, D. Highly Passivated N-Type Colloidal Quantum Dots for Solution-Processed Thermoelectric Generators with Large Output Voltage. Adv. Energy Mater 2019, 9, No. 1901244.

(41) Lin, Y. H.; Faber, H.; Rossbauer, S.; Anthopoulos, T. D. Solution-Processed $\mathrm{ZnO}$ Nanoparticle-Based Transistors via a RoomTemperature Photochemical Conversion Process. Appl. Phys. Lett. 2013, 102, No. 193516.

(42) Hirschmann, J.; Faber, H.; Halik, M. Concept of a Thin Film Memory Transistor Based on $\mathrm{ZnO}$ Nanoparticles Insulated by a Ligand Shell. Nanoscale 2012, 4, 444-447.

(43) Zhang, Y.; Chen, Q.; Alivisatos, A. P.; Salmeron, M. Dynamic Charge Carrier Trapping in Quantum Dot Field Effect Transistors. Nano Lett. 2015, 15, 4657-4663.

(44) Hwang, G. W.; Kim, D.; Cordero, J. M.; Wilson, M. W. B.; Chuang, C.-H. M.; Grossman, J. C.; Bawendi, M. G. Identifying and Eliminating Emissive Sub-Bandgap States in Thin Films of $\mathrm{PbS}$ Nanocrystals. Adv. Mater. 2015, 27, 4481-4486.

(45) Stavrinadis, A.; Pradhan, S.; Papagiorgis, P.; Itskos, G.; Konstantatos, G. Suppressing Deep Traps in PbS Colloidal Quantum Dots via Facile Iodide Substitutional Doping for Solar Cells with Efficiency $>10 \%$. ACS Energy Lett. 2017, 2, 739-744. 
(46) Oh, S. J.; Berry, N. E.; Choi, J.-H.; Gaulding, E. A.; Lin, H.; Paik, T.; Diroll, B. T.; Muramoto, S.; Murray, C. B.; Kagan, C. R. Designing High-Performance $\mathrm{PbS}$ and $\mathrm{PbSe}$ Nanocrystal Electronic Devices through Stepwise, Post-Synthesis, Colloidal Atomic Layer Deposition. Nano Lett. 2014, 14, 1559-1566.

(47) Nugraha, M. I.; Matsui, H.; Watanabe, S.; Kubo, T.; Häusermann, R.; Bisri, S. Z.; Sytnyk, M.; Heiss, W.; Loi, M. A.; Takeya, J. Strain-Modulated Charge Transport in Flexible $\mathrm{PbS}$ Nanocrystal Field-Effect Transistors. Adv. Electron. Mater. 2017, 3, No. 1600360.

(48) Shulga, A. G.; Kahmann, S.; Dirin, D. N.; Graf, A.; Zaumseil, J.; Kovalenko, M. V.; Loi, M. A. Electroluminescence Generation in PbS Quantum Dot Light-Emitting Field-Effect Transistors with Solid-State Gating. ACS Nano 2018, 12, 12805-12813.

(49) Bisri, S. Z.; Piliego, C.; Yarema, M.; Heiss, W.; Loi, M. A. Low Driving Voltage and High Mobility Ambipolar Field-Effect Transistors with PbS Colloidal Nanocrystals. Adv. Mater. 2013, 25, 43094314.

(50) Balazs, D. M.; Bijlsma, K. I.; Fang, H.-H.; Dirin, D. N.; Dobeli, M.; Kovalenko, M. V.; Loi, M. A. Stoichiometric Control of the Density of States in PbS Colloidal Quantum Dot Solids. Sci. Adv. 2017, 3, No. eaao1558.

(51) Shulga, A. G.; Derenskyi, V.; Salazar-Rios, J. M.; Dirin, D. N.; Fritsch, M.; Kovalenko, M. V.; Scherf, U.; Loi, M. A. An All-SolutionBased Hybrid CMOS-Like Quantum Dot/Carbon Nanotube Inverter. Adv. Mater. 2017, 29, No. 1701764.

(52) Koh, W.-k.; Saudari, S. R.; Fafarman, A. T.; Kagan, C. R.; Murray, C. B. Thiocyanate-Capped PbS Nanocubes: Ambipolar Transport Enables. Nano Lett. 2011, 11, 4764-4767.

(53) Nugraha, M. I.; Matsui, H.; Bisri, S. Z.; Sytnyk, M.; Heiss, W.; Loi, M. A.; Takeya, J. Tunable Doping in PbS Nanocrystal FieldEffect Transistors Using Surface Molecular Dipoles. APL Mater. 2016, 4, No. 116105.

(54) Oh, S. J.; Berry, N. E.; Choi, J.-H.; Gaulding, E. A.; Lin, H.; Paik, T.; Diroll, B. T.; Muramoto, S.; Murray, C. B.; Kagan, C. R. Designing High-Performance $\mathrm{PbS}$ and PbSe Nanocrystal Electronic Devices through Stepwise, Post-Synthesis, Colloidal Atomic Layer Deposition. Nano Lett. 2014, 14, 1559-1566.

(55) Liu, Y.; Gibbs, M.; Puthussery, J.; Gaik, S.; Ihly, R.; Hillhouse, H. W.; Law, M. Dependence of Carrier Mobility on Nanocrystal Size and Ligand Length in Pbse Nanocrystal Solids. Nano Lett. 2010, 10, 1960-1969.

(56) Hines, M. A.; Scholes, G. D. Colloidal PbS Nanocrystals with Size-Tunable Near-Infrared Emission: Observation of Post-Synthesis Self-Narrowing of the Particle Size Distribution. Adv. Mater. 2003, 15, 1844-1849. 